\title{
Pluriatividade, Pobreza Rural e Serviço Doméstico Remunerado
}

Carlos Alves do Nascimento ${ }^{1}$

Resumo - Este trabalho se propôs analisar, com base nos microdados da Pesquisa Nacional por Amostra de Domicílios (PNAD) - anos 19921999 e 2001 -, a participação da renda do serviço doméstico remunerado entre determinados tipos de famílias rurais pobres que apresentaram taxas de crescimento negativas nos anos 90, demonstrando que, em diversos casos, a renda do serviço doméstico explica melhor a redução da pobreza rural do que as transferências governamentais (aposentadorias e pensões). Para tanto, realizamos uma breve análise da evolução dos diferentes tipos de famílias extensas rurais (e pobres) nos anos 90, além de uma análise comparativa entre as Grandes Regiões do país no tocante às rendas média e per capita dos diferentes tipos de famílias rurais adotando como referência o ano de 2001. Além disso, procuramos mostrar que a redução de famílias pobres agrícolas se deve, neste caso, também ao fato destas estarem se tornando famílias de não-ocupados, residentes no meio rural, e não somente em virtude de êxodos agrícola (substituição de atividades agrícolas por atividades não-agrícolas) e/ou rural-urbano. Para testar estas hipóteses, adotamos como referência a linha de pobreza construída por Takagi et al (2001) - de U\$ 1,08 - e a nova tipologia de famílias extensas desenvolvida pelo Projeto Rurbano.

\footnotetext{
${ }^{1}$ Doutorando do curso de Desenvolvimento Econômico, Espaço e Meio Ambiente do IE/Unicamp. E-mail: can@eco.unicamp.br
} 
Palavras-chave: Pluriatividade; Serviço Doméstico Remunerado; Pobreza Rural.

Abstract - This paper tries to analyze, based on the micro data of the Pesquisa Nacional por Amostra de Domicilios (PNDA) - years 1992-1999 and 2001 - the share of the paid domestic service income between some types of poor rural families that presented negative growing taxes in the 90s, showing that in different cases, the paid domestic service income better explains the reduction of rural poverty than governmental transferences (retirements and pensions). We made a brief analysis of the evolution of different types of rural extensive families (and poor) in the 90s, besides a comparative analysis among the big regions of the country with respect to the average and per capita incomes of different types of rural families, adopting as reference 2001. We tried also to demonstrate that the reduction of the poor rural families is due to, in this case, because they are becoming non-occupied families, residents in the rural areas, and not only because of agricultural exodus (substitution of the agricultural activities for the non-agricultural activities) and/or rural-urban exodus. To test these hypotheses, we adopted as reference the rural poverty line created by Takagi et al (2001) - of U\$ 1,08 - and the new tipology of extensive families developed by the Projeto Rurbano.

Key Words: pluralactivity, paid domestic service and rural poverty.

Jel Classification: $R 2$

\section{1 -Introdução}

Este trabalho faz parte de um projeto amplo de pesquisas denominado sinteticamente de Projeto Rurbano ${ }^{2}$, e se propôs analisar, com base nos microdados da Pesquisa Nacional por Amostra de Domicílios (PNAD) - anos 1992-1999 e 2001 -, a participação da renda do serviço

\footnotetext{
${ }^{2}$ É um projeto temático denominado “Caracterização do Novo Rural Brasileiro”, do Núcleo de Economia Agrícola do IE-Unicamp, que conta com financiamento da FAPESP e do PRONEX/CNPq-FINEP.
} 
doméstico remunerado entre determinados tipos de famílias rurais pobres que apresentaram taxas de crescimento negativas nos anos 90. Para tanto, realizamos uma rápida análise da evolução dos diferentes tipos de famílias extensas rurais nos anos 90, além de uma análise comparativa entre as Grandes Regiões do país no tocante às rendas média e per capita dos diferentes tipos de famílias extensas rurais adotando como referência o ano de 2001. Além disso, procuramos mostrar também que a redução de famílias pobres agrícolas se deve, neste caso, também ao fato destas estarem se tornando famílias de não-ocupados ${ }^{3}$, embora permanecendo residentes no meio rural.

Para testar estas hipóteses, além de adotarmos como referência a linha de pobreza construída por Takagi et al (2001) - de U\$ 1,08 -, adotamos a nova tipologia de famílias extensas ${ }^{4}$ desenvolvida pelo Projeto Rurbano, a qual compreende 4 tipos de famílias pluriativas, cada qual correspondendo a uma combinação específica de atividades, a saber: agrícola + agrícola (pluriatividade tradicional), agrícola + não-agrícola (intersetorial sem serviço doméstico remunerado - ou SDR), agrícola com SDR, agrícola + não-agrícola + SDR (intersetorial com SDR). As famílias não-agrícolas, por sua vez, foram subdivididas em não-agrícolas sem SDR e não-agrícolas com SDR ${ }^{5}$.

\footnotetext{
${ }^{3}$ São famílias que não têm nenhum membro classificado (pela PNAD) como empregador, ou conta-própria, ou empregado. Ou seja, são famílias formadas por não-ocupados, procurando ou não emprego (na semana de referência da PNAD). Se na família houver algum membro empregador, tal família é classificada como empregadora. Não havendo nenhum empregador, mas pelo menos um conta-própria, a família é compreendida como de contaprópria. Na ausência de empregador e de conta-própria a família será considerada de empregados caso algum membro esteja ocupado na semana de referência da PNAD.

${ }^{4}$ A unidade de análise utilizada para os estudos da pluriatividade, desenvolvidos no âmbito do Projeto Rurbano, passou a ser o que se convencionou chamar de família extensa, de modo que compreende, para além da família nuclear, os parentes desta que vivem no mesmo domicílio (não obstante formem outro casal) e os agregados - ou seja, são as pessoas que habitam em um mesmo domicílio, independentemente do grau de parentesco que possuem entre si, excluídas as empregadas domésticas e pensionistas, bem como seus familiares. Para um tratamento detalhado da elaboração do conceito de família extensa no âmbito do Projeto Rurbano e, também, sobre os problemas metodológicos envolvidos na análise da pluriatividade segundo os critérios da PNAD, ver Del Grossi \& Gaziano da Silva (1998). Para uma síntese da discussão, consultar Nascimento et al (2001).

${ }^{5}$ Os tipos de famílias agrícolas, pluriativas e não-agrícolas, classificam-se segundo a posição na ocupação (empregadoras, conta-próprias e empregados). Neste trabalho consideramos apenas as famílias de conta-próprias e empregados em virtude de que juntas formavam a maior fração $(84,00 \%)$ do total de famílias residentes no rural agropecuário não metropolitano do Brasil, segundo a PNAD de 2001.
} 
Consideramos famílias pluriativas tradicionais (agrícola + agrícola) aquelas em que seus membros combinam apenas atividades agrícolas com trabalho assalariado também agrícola ${ }^{6}$; denominamos de família pluriativa intersetorial sem SDR (agrícola + não-agrícola) a família em que pelo menos um membro se ocupa em atividades agrícolas e pelo menos um outro se ocupa em atividades não-agrícolas e que nenhum dos membros se ocupa em SDR; a família cujos membros combinam atividades agrícolas apenas com SDR consideramos família pluriativa com SDR (agrícola + SDR); por fim, chamamos de família pluriativa intersetorial com SDR aquela cujos membros combinam atividades agrícolas com SDR e com outras atividades não-agrícolas (agrícola + não-agrícola + SDR). Essas reformulações metodológicas objetivaram captar as alterações sofridas pelos diferentes tipos de combinações de atividades agrícolas e não-agrícolas nos anos 90, especialmente das combinações que envolvem o SDR. Privilegiamos o SDR na construção da nova tipologia de famílias em virtude de ser esta a ocupação que mais cresceu significativamente, do ponto de vista estatístico, em todas as áreas rurais do país segundo várias pesquisas do Projeto Rurbano. O crescimento e expansão do número de casos de emprego doméstico no país tem se revelado um fenômeno tão expressivo e relevante que o próprio IBGE resolveu classificá-lo, a partir das novas PNADs de 1992 em diante, como uma posição na ocupação em separado da categoria de trabalhadores ocupados.

Para efeito de comparação da evolução da pluriatividade nos anos 90 (e suas diversas combinações conforme tratado acima) entre as Grandes Regiões brasileiras, esta pesquisa adotou a mesma subdivisão regional utilizada por Del Grossi (1999): a) $\operatorname{Norte}^{7}$ (N): Rondônia, Acre, Amazonas, Roraima, Pará e Amapá; b) Nordeste (NE): Maranhão, Piauí, Ceará, Rio Grande do Norte, Paraíba, Pernambuco, Alagoas, Sergipe e Bahia; c) Sudeste modificada (RJ + ES + MG): Rio de Janeiro, Minas Gerais e Espírito Santo; d) São Paulo (SP): São Paulo; e) Sul (SU): Paraná,

\footnotetext{
${ }^{6}$ Não consideramos pluriatividade tradicional entre as famílias de empregados, somente entre os conta-próprias (Nascimento et alli, 2001).

${ }^{7}$ As PNADs não levantam as áreas rurais dos estados desta região, e por isso esta região não será citada quando das análises das áreas rurais do Brasil.
} 
Santa Catarina e Rio Grande do Sul; e f) Centro-Oeste (CO): Mato Grosso do Sul, Mato Grosso, Goiás, Distrito Federal e Tocantins.

\section{2 - A Evolução das Famílias Extensas Rurais nos anos 90}

Ao trabalhar com a nova tipologia de famílias desenvolvida no âmbito do Projeto Rurbano, pudemos mostrar (Nascimento, 2002) ${ }^{8}$ que, a despeito da generalizada estabilidade da pluriatividade ${ }^{9}$ no agregado para o Brasil como um todo, ao desagregá-la por diferentes tipos de famílias pluriativas e estas pelas Grandes Regiões redefinidas do país, foi possível observar trajetórias diferenciadas entre os distintos tipos de famílias pluriativas, na série temporal analisada (1992-1999; IBGE-PNAD).

Os resultados conclusivos do nosso estudo (Nascimento, 2002), realizado a partir dos microdados das PNADs (1992-1999 $\left.{ }^{10}\right)$, não foram muito alentadores a respeito da pluriatividade no Brasil ${ }^{11}$ : estagnado no Centro-Oeste; em queda generalizada no Sul; no Nordeste sustentou-se com o SDR; e, de resto, apresentou um desempenho positivo - no sen-

\footnotetext{
${ }^{8}$ Dissertação de mestrado que ganhou "Menção Honrosa" no Congresso da SOBER de 2002, em Passo Fundo/RS. A mesma foi defendida em fevereiro de 2002, no IE/Unicamp, sob orientação do Prof. Dr. José Graziano da Silva.

${ }^{9}$ Para uma síntese sobre o conceito de pluriatividade, ver Nascimento (2002).

${ }^{10}$ Os aspectos tendenciais (taxas significativas de crescimento ou de decrescimento), referentes à série 1992-1999, fundamentaram-se em estimativas dos coeficientes angulares de equações de tipo log-linear do total da população em função do tempo. O termo significativo, ao qual doravente nos referiremos, expressa o fato de que a taxa de crescimento (ou diminuição) encontra-se dentro dos níveis de significância estabelecidos $(5 \%, 10 \%$ e $20 \%)$, explicitando a existência de tendência na evolução dos dados. ${ }^{11}$ Optamos por não atualizar ainda a série para 1992-2001 em virtude de que, com o censo de 2000, o IBGE ainda está revisando os pesos das PNADs da série completa dos anos 90, inclusive para os anos 1992, 1993 e 1995 que já tinham os novos pesos da recontagem de 1996. Isso significa que o próprio IBGE prefere basear seus cálculos das estimativas de projeção das amostras das PNADs de 1992 a 1999 no Censo de 2000 à recontagem de 1996. Como o IBGE ainda não divulgou os novos pesos a partir do censo de 2000, e para não divulgarmos resultados baseados em dados com projeções discrepantes do que seriam se processados com os pesos calculados a partir do censo de 2000, optamos por manter a série sem 2001, já que a projeção para este ano baseia-se no Censo de 2000 e os anos anteriores estão projetados a partir da recontagem de 1996. Contudo, para o objetivo desse trabalho, a adoção da série 1992-1999 sem a PNAD de 2001 para a evolução do número de famílias rurais, não afeta no essencial. Por outro lado, todas as observações que serão feitas relativas às rendas média e per capita familiar serão feitas tendo por base a PNAD de 2001. Análises comparativas semelhantes utilizando a PNAD de 1999 foram realizadas em Nascimento (2002) - os resultados são bastante assemelhados, com raras e pequenas variações.
} 
tido de que aumentou a pluriatividade intersetorial sem SDR - apenas parcialmente no Sudeste (sem São Paulo) e plenamente em São Paulo. Porém, dado estes resultados, o destaque deu-se para a região Nordeste, a qual foi a única região que confirmou plenamente a hipótese do nosso estudo - de que o SDR constituiu-se na ocupação que logrou, ao longo dos anos 90, evitar o declínio da pluriatividade. Pudemos mostrar que no Nordeste cresceu unicamente - e de forma significativa - as famílias pluriativas (agrícola + SDR), de conta-próprias e de empregados, além de ter sido a única região também em que o crescimento significativo das famílias de empregados não-agrícolas foi puxado exclusivamente pelo SDR (Tabela 1).

Além destas conclusões gerais, mostramos também que, por mais que reflita uma pluriatividade não "virtuosa" a combinação de atividades agrícolas com SDR (não gerador de renda, mas apenas transferidor), este tipo de pluriatividade revelou-se, na maioria dos casos analisados, uma estratégia de reprodução familiar melhor, em termos de fonte de renda, do que a família ser essencialmente agrícola. Vale dizer, por pior que seja a combinação agrícola com SDR, esta mostra-se melhor para a composição da renda familiar, em muitos casos, do que ser exclusivamente famílias de bóias-frias/volantes (ou agricultores contapróprias) - apesar deste ser um trabalho regulamentado (Estatuto do Trabalhador Rural), e o SDR não totalmente ${ }^{12}$.

Em outras palavras, a estratégia de diversificar as atividades fora da agricultura, mesmo sendo com o SDR, pode estar significando uma "saída” para se preservar a exploração agrícola, assim como também manter as famílias no meio rural, sustando a necessidade de migrações para as cidades. Esta é uma realidade para muitas famílias rurais em todas as Grandes Regiões do Brasil, em especial na região Nordeste, nos anos 90 (Nascimento, 2002).

Por fim, as considerações acerca das famílias extensas pluriativas e das suas rendas médias e per capita, suscitaram uma questão importante: a de que estudos sobre a pluriatividade em termos agregados podem

${ }^{12}$ Com a Constituição Federal de 1988 os trabalhadores domésticos obtiveram avanço em relação à Lei que rege o Trabalho Doméstico Remunerado (Lei nr 5.859 de 11/12/ 1972), no tocante aos direitos trabalhistas. No entanto, mesmo assim esta categoria profissional ainda está longe de ser equiparada às demais (Martins, 2000). 
conduzir a conclusões generalizantes não plenamente condizentes com a complexidade do fenômeno. Um exemplo disso é o trabalho de Kageyama (2001), que estudou o efeito da pluriatividade sobre três variáveis: renda, pobreza e condições de vida. De uma forma geral, a conclusão a que chegou a autora foi a de que a "pluriatividade, embora sempre significativa nos modelos, teve contribuições marginais modestas no aumento da renda e redução da pobreza” (p. 56).

Tabela 1 - Taxas de crescimento ${ }^{\mathrm{a}}$ dos tipos de famílias extensas: Brasil e Grandes Regiões, 1992/99.

(Rural Agropecuário ${ }^{13}$ Não-metropolitano)

\begin{tabular}{|c|c|c|c|c|c|c|c|c|c|}
\hline TIPO DE FAMÍLIA & BR & $\mathrm{NE}$ & SE & - SP & SP & SU & $\mathrm{U}$ & \multicolumn{2}{|c|}{$\mathrm{CO}$} \\
\hline Conta-Própria & 0,3 & $1,6^{* *}$ & $-1,7$ & $* * *$ & 1,5 & $-2,0$ & $* * *$ & 1,0 & \\
\hline Agrícola & $-0,5$ & 1,7 & $-2,9$ & $* * *$ & $-4,9 * * *$ & $-2,9$ & $* * *$ & 1,1 & * \\
\hline Pluriativo & 0,0 & 0,7 & $-1,0$ & & $2,8^{*}$ & $-2,2$ & $* *$ & $-1,8$ & \\
\hline Agrícola + Agrícola & 0,7 & 1,8 & 1,1 & & 0,0 & $-4,0$ & $* * *$ & $-2,9$ & \\
\hline Agrícola + não-agrícola & $-0,4$ & 0,2 & $-2,2$ & & $4,7^{*}$ & $-2,1$ & & $-0,9$ & \\
\hline Agrícola + SDR & $2,3 * *$ & $4,5 * *$ & $-1,0$ & & - & 2,5 & & - & \\
\hline Agrícola. + não-agr. + SDR & $-0,2$ & 2,5 & - & & - & - & & - & \\
\hline Não-agrícola & $7,1^{* * *}$ & $5,9 * * *$ & 2,2 & & $15,5^{* * *}$ & 9,4 & $* * *$ & 9,4 & $* * *$ \\
\hline Não-agrícola com SDR & $6,9 * * *$ & $5,7 * * *$ & 2,1 & & $15,7^{* * *}$ & 8,9 & $* * *$ & 10,2 & $* * *$ \\
\hline Não-agrícola sem SDR & $10,2 * * *$ & - & 4,8 & & - & - & & - & \\
\hline Empregados & $1,5^{* * *}$ & $-0,1$ & 2,2 & $* * *$ & $1,9 * * *$ & 3,2 & $* * *$ & 2,8 & $* * *$ \\
\hline Agrícola & $-0,9^{*}$ & $-2,6^{*}$ & 0,4 & & $-2,3 * *$ & 0,5 & & 1,2 & $* * *$ \\
\hline Pluriativo & 1,5 & 1,4 & 3,8 & *** & $-0,3$ & $-1,0$ & & 3,2 & \\
\hline Agrícola + não-agrícola & 0,6 & 1,2 & 3,5 & $* *$ & $-1,8$ & $-3,3$ & $* *$ & 0,8 & \\
\hline Agrícola + SDR & $3,7^{* * *}$ & $4,2 *$ & 4,0 & $* * *$ & 2,0 & 3,4 & & 4,6 & \\
\hline Agrícola. + não-agr. + SDR & $-0,9$ & - & 3,6 & & - & - & & - & \\
\hline Não-agrícola & $7,0 * * *$ & $5,8 *$ & 6,7 & $* * *$ & $7,7 * * *$ & 7,6 & $* * *$ & 10,5 & $* * *$ \\
\hline Não-agrícola com SDR & $6,2^{* * *}$ & 5,4 & 4,6 & $* *$ & $7,7^{* * *}$ & 6,8 & $* * *$ & 8,8 & $* * *$ \\
\hline Não-agrícola sem SDR & $10,6^{* * *}$ & $9,5^{* * *}$ & 12,3 & $* * *$ & $7,7 * * *$ & 12,9 & $* * *$ & 16,6 & $* * *$ \\
\hline
\end{tabular}

Nota: exclusive as famílias sem declaração de renda e tipos de família com menos de 5 observações a) estimativa do coeficiente de uma regressão log-linear contra o tempo. Neste caso, o teste t indica a existência ou não de uma tendência nos dados.

$* * *, * *, *$ significam respectivamente $5 \%, 10 \%$ e $20 \%$ de significância.

Fonte: Nascimento, 2002.

${ }_{13}$ A soma de núcleos mais rural exclusive (classificações do IBGE) denominamos de rural agropecuário (ou rural "profundo") para destacar a vinculação dos domicílios aí existentes a um único proprietário (público ou privado), como é o caso das colônias de fazendas, por exemplo. 
Acreditamos, porém, que a autora chegou a esta conclusão em razão do uso da pluriatividade no agregado, sem considerar os diferentes tipos de pluriatividade, os quais, como pudemos ver, apresentam características e comportamentos heterogêneos que podem se "anular" mutuamente dependendo do que se esteja investigando. Nesse sentido, entendemos que a autora obteria resultados mais próximos da realidade - resultados diferenciados - se considerasse não o agregado, mas os diferentes tipos de pluriatividade, segmentado pelas diferentes regiões ${ }^{14}$. É o que faremos adiante.

Feitas estas primeiras considerações, a seguir realizaremos algumas observações comparativas entre as Grandes Regiões corrigidas e o Brasil, no que respeita ao nível e composição das rendas média e per capita das famílias extensas agrícolas, pluriativas e não-agrícolas, com base nos microdados da PNAD de 2001. Em seguida, verificaremos os possíveis reflexos do crescimento da pluriatividade (agrícola + SDR), e de seus níveis de renda, sobre as famílias rurais pobres. Por fim, veremos também que o rápido crescimento das famílias de não-ocupados residindo no meio rural também pode ser uma explicação para a redução da pobreza rural entre as famílias agrícolas.

\section{3 - Renda média familiar}

Os gráficos 01 e 02 comparam as rendas médias das famílias agrícolas, pluriativas e não-agrícolas, segundo a categoria ocupacional (conta-próprias e empregados), domicílio (rural agropecuário não metropolitano) e as Grandes Regiões redefinidas do Brasil. Pode-se ver que em todas as situações as rendas médias das famílias pluriativas e não-agrícolas são superiores às rendas médias das famílias agrícolas. As rendas médias das famílias pluriativas ultrapassam também as rendas médias das famílias não-agrícolas, de forma quase generalizada - especialmente entre as famílias de empregados onde a diferença entre os dois tipos de famílias é maior. No Sul, as maiores rendas médias são das famílias

\footnotetext{
${ }^{14}$ Faz-se necessário também pesquisas sobre o comportamento dos diversos tipos de pluriatividade dentro de cada região, que certamente serão encontrados resultados diferenciados intraregionalmente.
} 
não-agrícolas (empregados), porém, não muito distantes das rendas médias pluriativas. Por fim, as menores rendas médias, em todos os casos, são das famílias nordestinas - abaixo da média nacional. Estas informações evidenciam a importância da pluriatividade como estratégia de geração de renda das famílias rurais de todas as regiões.

Gráfico 01 - Renda média dos tipos de famílias extensas de conta-próprias, 2001.

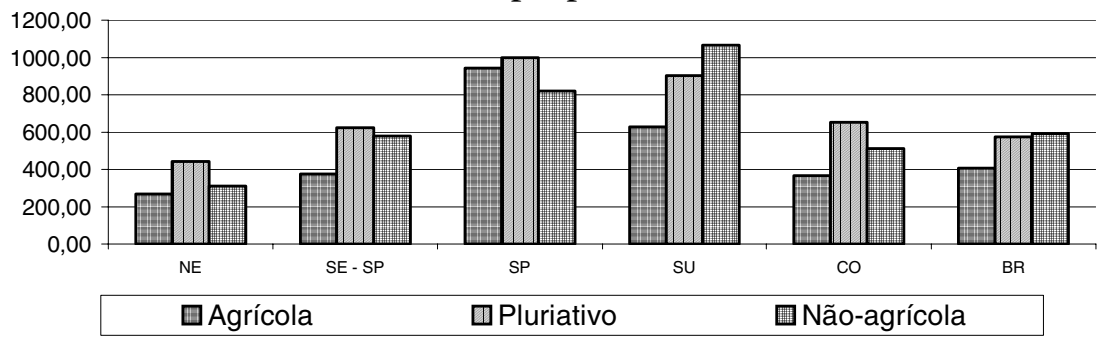

Fonte: PNAD 2001. Projeto Rurbano - IE/Unicamp

Gráfico 02 - Renda média dos tipos de famílias extensas de empregados, 2001.

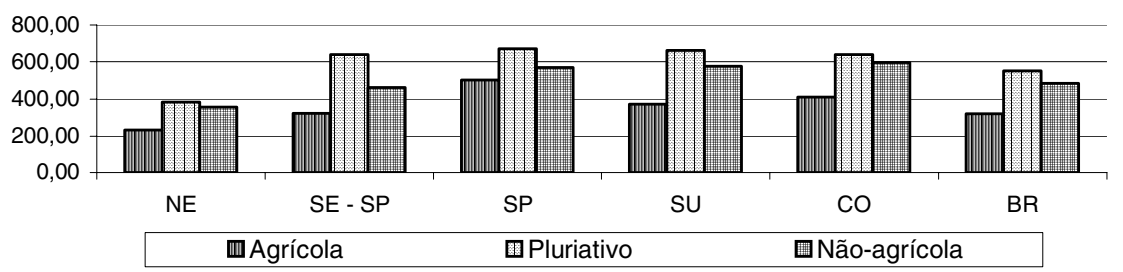

Fonte: PNAD 2001. Projeto Rurbano - IE/Unicamp

O gráfico 03 compara as rendas médias das famílias de conta-próprias agrícolas e pluriativas intersetoriais (com e sem SDR). Em quase todas as regiões, as famílias agrícolas e pluriativas com SDR detêm as menores rendas. Merecem destaque as regiões Nordeste e Sudeste (sem São Paulo), onde as rendas médias de ambos os tipos familiares pluriativos intersetoriais (com e sem SDR) estão, em 2001, praticamente no mesmo patamar e acima das rendas médias das famílias agrícolas. Na região Nordeste, além de só crescer significativamente a pluriatividade (agrícola + SDR), como já mostramos anteriormente, o 
que existe de pluriatividade intersetorial sem SDR (agrícola + não-agrícola) não apresenta uma renda média substancialmente superior à anterior. Além disso, somente na região Nordeste as rendas médias dos três tipos de famílias encontra-se abaixo da média nacional. A explicação para estas evidências quanto às famílias rurais nordestinas se deve à quase inexistência de outras ocupações não agrícolas que não aquelas legadas ao setor de serviços e em particular de serviços pessoais, como já mostraram Graziano da Silva e Del Grossi (2001). Ou seja, o Nordeste pouco tem de indústrias rurais ${ }^{15}$ e o pouco que tem de agroindústria está ligada ao setor sucroalcooleiro, que atravessa uma grave crise econômica que está levando à sua destruição em muitos lugares (Lima, 2001).

No Nordeste, a renda média das famílias pluriativas (agrícola + SDR) é de R \$374,40, inferior ao da pluriatividade intersetorial sem SDR (R $\$ 452,71)$ e bastante acima da renda média das famílias agrícolas (R\$268,49), sugerindo que, no Nordeste, por mais "não-virtuosa" que seja a combinação de atividades agrícolas com o SDR, esta ainda é melhor do que a estratégia familiar de geração de renda restrita às rendas agrícolas.

Gráfico 03 - Renda média das famílias extensas de conta-próprias agrícolas e pluriativas, 2001.

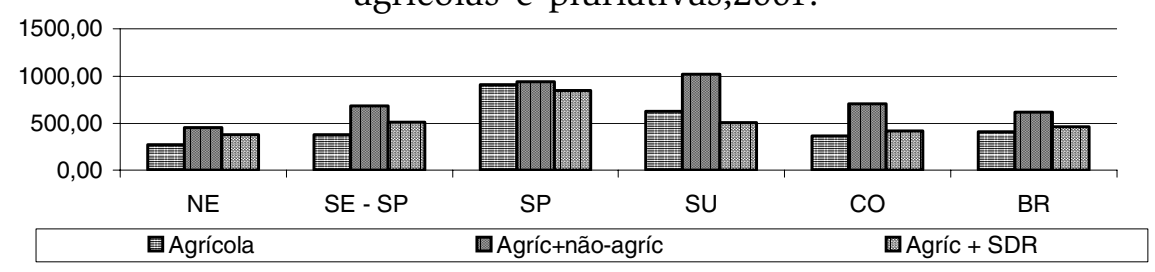

Fonte: PNAD 2001. Projeto Rurbano - IE/Unicamp

Da mesma forma, entre as famílias de empregados, conforme podese ver no gráfico 04, a diversificação das fontes de renda através do SDR, em 2001, tem-se revelado importante para muitas famílias ru-

\footnotetext{
${ }^{15}$ Fernandes Filho (2001) chama atenção para a importante - em termos econômico e social - existência de indústrias rurais familiares no Nordeste - porém, com precário apoio público.
} 
rais em todo o país, especialmente no Nordeste, onde só tem crescido esse tipo de pluriatividade (1992-1999) - importa lembrar que também na região Sudeste cresceu significativamente a pluriatividade (agrícola + SDR) entre as famílias de empregados (Tabela 1). Vale a pena observar também que enquanto no Sudeste, em São Paulo e no Centro-Oeste a renda média da pluriatividade intersetorial sem SDR, em 2001, é quase o dobro da renda média da pluriatividade (agrícola + SDR), no Nordeste e no Sul elas são bastante próximas, ressaltando o importante peso do SDR.

Gráfico 04 - Renda média das famílias extensas de empregados agrícolas e pluriativas, 2001.

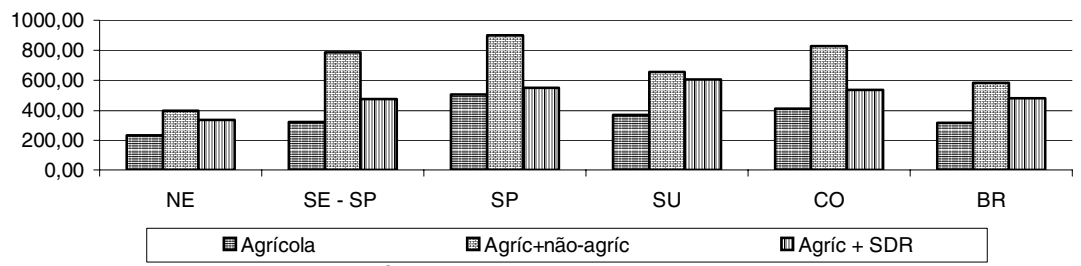

Fonte: PNAD 2001. Projeto Rurbano - IE/Unicamp

\section{4 - Renda média familiar per capita}

Em relação aos diferentes tipos de famílias pluriativas, conta-próprias e empregados, os gráficos 05 e 06 evidenciam o importante peso da renda do SDR em todas as Grandes Regiões redefinidas, quando se comparam as famílias pluriativas (agrícola + SDR) com as famílias estritamente agrícolas. Comparando as rendas médias familiares per capita das famílias agrícolas e pluriativas com SDR, os gráficos 05 e 06 mostram que, de maneira geral, as rendas médias per capita das famílias pluriativas com SDR (agrícola + SDR) são maiores que as das famílias exclusivamente agrícolas - exceção das famílias de conta-próprias de São Paulo e do Sul. 
Gráfico 05 - Renda média familiar per capita dos diferentes tipos de famílias extensas de conta-próprias agrícolas e pluriativas, 2001.

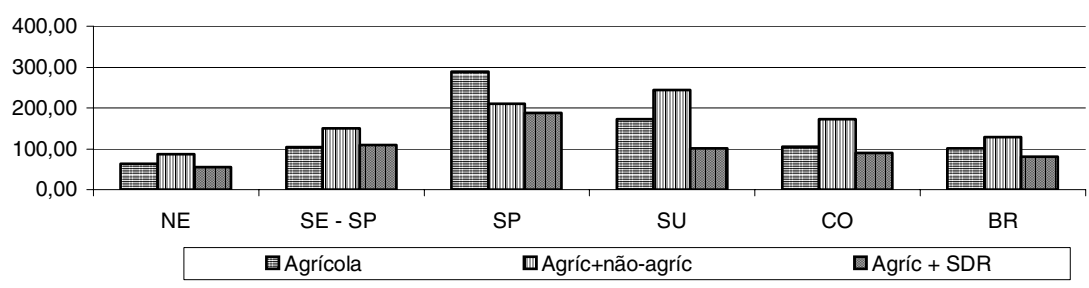

Fonte: PNAD, 2001. Projeto Rurbano - IE/Unicamp.

Gráfico 06 - Renda média familiar per capita dos diferentes tipos de famílias extensas de empregados agrícolas e pluriativos, 2001.

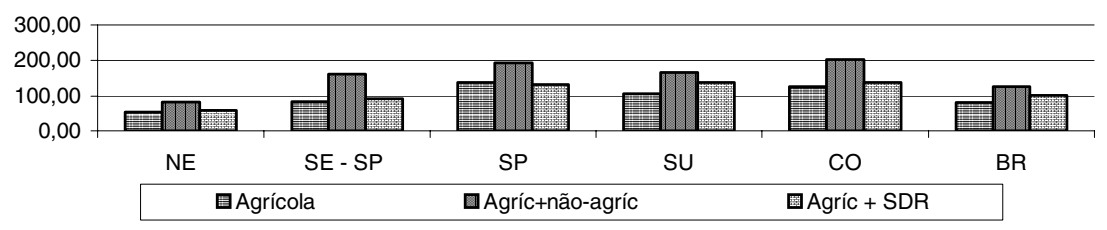

Fonte: PNAD, 2001. Projeto Rurbano - IE/Unicamp.

O gráfico 07 mostra a composição das rendas médias ${ }^{16}$ das famílias de conta-próprias pluriativas com SDR (agrícola + SDR), em 2001. Podese verificar que nas regiões Nordeste e Sul um terço das rendas das famílias decorrem do SDR. Pode-se ver também que em quase todas as regiões a renda média do SDR é bastante superior às rendas médias provenientes de pensões e aposentadorias e outras fontes, com exceção do Sudeste (sem São Paulo) onde as rendas decorrentes de transferências governamentais (aposentadorias e pensões) exibem uma participação inferior apenas à renda agrícola, na composição total das rendas das famílias em apreço.

${ }^{16}$ A composição das rendas médias familiares per capita é idêntica à composição das rendas médias. Isto só não é verdadeiro para os valores absolutos dos dois tipos de rendas. No entanto, as composições destas rendas em termos relativos são seguramente idênticas. 
Gráfico 07 - Composição da renda das famílias de conta-próprias pluriativas (agrícola + SDR), 2001.

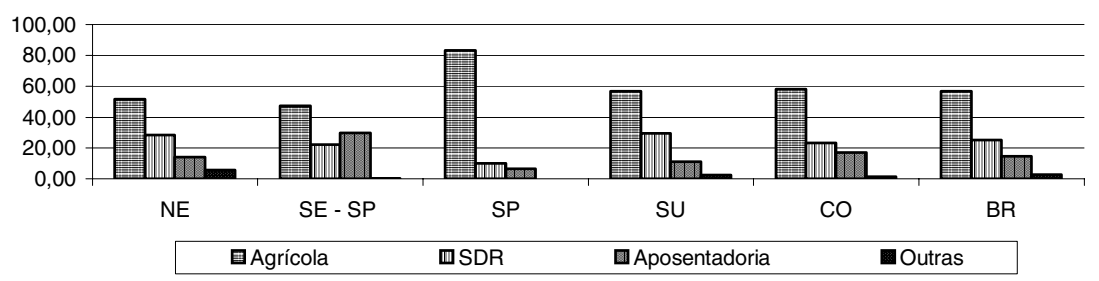

Fonte: PNAD, 2001. Projeto Rurbano - IE/Unicamp.

O gráfico 08 mostra que na composição das rendas médias das famílias de empregados pluriativos com SDR (agrícola + SDR) em 2001, o SDR se apresenta, em todas as Grandes Regiões, como a segunda maior fonte de renda, bem acima das fontes governamentais e outras - lembrando que no Sudeste as rendas advindas de aposentadorias e pensões eram maiores que as rendas do SDR entre as famílias de conta-próprias do mesmo tipo, em 2001.

Gráfico 08 - Composição da renda média das famílias de empregados pluriativas (agrícola + SDR), 2001.

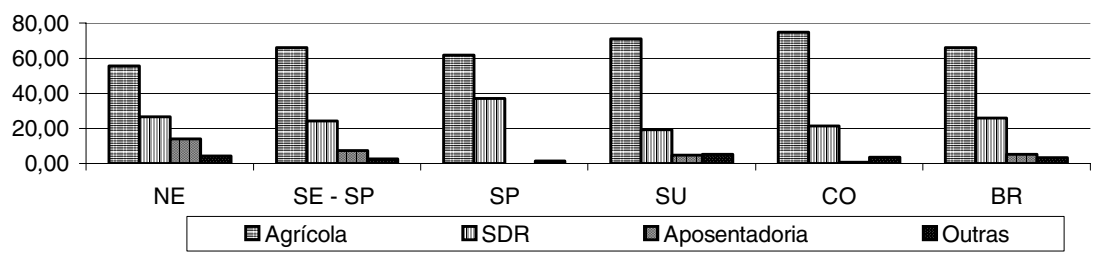

Fonte: PNAD, 2001. Projeto Rurbano - IE/Unicamp.

\section{5 - Famílias extensas pobres}

Em 1999, dos 42,8 milhões de famílias residentes em todo o Brasil, 7,6 milhões $(17,7 \%)$ declararam domicílio nas áreas rurais nãometropolitanas. Desse universo populacional, 48,2\%, 37,8\% e 10,0\% correspondiam, respectivamente, às famílias de conta-próprias, assalariados e de não-ocupados (o restante, $4,1 \%$, são de famílias de empregadores). Em relação ao mesmo universo de famílias, 36,4\% 
(2,7 milhões) pertenciam ao conjunto de famílias pobres, segundo a linha de pobreza adotada. Esse contingente de famílias pobres ficava distribuído da seguinte forma entre os tipos de famílias aqui tratados: 50,1\% entre as famílias de conta-próprias; 42,3\% entre as famílias de assalariados; 7,6\% entre as famílias de não-ocupados.

Do ponto de vista das Grandes Regiões do país, aquele contingente de famílias rurais não-metropolitanas pobres $(2,7$ milhões $)$ estava, em 1999, distribuído da seguinte maneira: 65,3\% no Nordeste, 14,3\% no Sudeste (sem São Paulo), 3,2 \% em São Paulo, 10,5 \% no Sul e 6,6\% no Centro-Oeste.

A pobreza no Brasil, nos anos 90, aumentou consideravelmente. Seu crescimento, porém, ao contrário do que se poderia imaginar concentrou-se principalmente nas Regiões Metropolitanas (RM) do país, mas também nas pequenas e médias cidades brasileiras. Por outro lado, a novidade da década passada foi que nas áreas rurais não metropolitanas em seu conjunto não se registrou crescimento da pobreza (Del Grossi et al, 2002). As explicações para esta novidade são variadas:

i) O contingente de famílias agrícolas pobres diminuiu em decorrência do abandono das atividades agrícolas pelas não-agrícolas (Del Grossi et al, 2002);

ii) a ocorrência de estabilidade da pobreza rural pode ser, em muitos casos, explicado pelo avanço das transferências governamentais na forma de aposentadorias e/ou pensões previdenciárias (Delgado \& Cardoso, 2000);

iii) ainda ocorre êxodo rural, embora de forma localizada em algumas regiões do Brasil, como no Sul do país. Nestas regiões, o número de famílias pobres pode estar se retraindo em decorrência da migração de parcela de famílias pobres (Graziano da Silva et al, 2000).

Estas explicações são plausíveis para dar conta de muitos dos casos de retração e/ou estabilidade da pobreza rural, como os descritos abaixo.

A Tabela 2 mostra que as famílias de conta-próprias pobres com renda per capita diária inferior a U\$ 1,08 , residentes nas áreas rurais não metropolitanas, experimentaram taxas de decrescimento significativas 
nas regiões Sudeste ( $8,8 \%$ a.a.), São Paulo (11,8\% a.a.) e Sul $(4,2 \%$ a.a.), no período $1995-1999^{17}$.

A mesma tabela também mostra que, do ponto de vista dos tipos de famílias de conta-próprias (agrícolas, pluriativas e não-agrícolas), é notável a generalizada diminuição das famílias pobres agrícolas em quase todas as regiões do país, salvo na região Nordeste e Centro-Oeste, onde permaneceu estável, do ponto de vista estatístico, no período de análise. Observa-se também uma relativa estabilidade nas famílias pluriativas e não-agrícolas em praticamente todas as Grandes Regiões do país. Exceção da região Sudeste, que verificou um decréscimo significativo entre as famílias pobres pluriativas (11,2\% a.a.), e da região Nordeste onde ocorreu um aumento significativo das famílias pobres do mesmo tipo (5,3\% a.a.).

A forte redução do número de famílias pobres de conta-próprias agrícolas nas regiões Sudeste ( $8,7 \%$ a.a.), São Paulo (18,4\% a.a.) e Sul ( $5,0 \%$ a.a.) provavelmente decorre da redução do contingente das famílias de conta-próprias agrícolas nestas regiões no período 1992-99 (ver Tabela 1). O que nos leva a supor que o êxodo agrícola ${ }^{18}$ está levando à redução da pobreza entre as famílias agrícolas e, ao mesmo tempo, sem elevação da mesma entre as famílias de conta-próprias não-agrícolas e pluriativas nas referidas regiões ${ }^{19}$.

A Tabela 2 mostra ainda que as famílias pobres de assalariados residentes nas áreas rurais não metropolitanas permaneceram relativamente estabilizadas, do ponto de vista estatístico, em quase todas as regiões do país, exceto nas regiões Sul e Nordeste onde houve um crescimento significativo destas famílias a uma taxa de 1,8\% a.a. e 2,6\% a.a., respectivamente, no período 1995-99.

\footnotetext{
${ }^{17}$ Importa notificar que optamos por considerar, para esse caso das famílias extensas pobres, apenas a série 1995-1999 e desconsiderar os anos 1992 e 1993, com a intenção de evitarmos incorrer em erros graves, posto que parte do crescimento das rendas captado pelas PNADs de 1992 a 1995 se deve ao fato de que o deflator utilizado (INPC restrito) pode não ter captado adequadamente a inflação da época da implantação do Plano Real no ano de 1994. A linha de pobreza adotada aqui é a renda per capita de U\$ 1,08 por dia (cf. Takagi et al, 2001 e Del Grossi et al, 2002).

${ }^{18}$ Substituição de atividades agrícolas por não-agrícolas, confirmando a hipótese de Del Grossi et al (2002).

${ }^{19}$ Veremos mais adiante que houve também um rápido crescimento das famílias de não ocupados.
} 
Tabela 2 - Taxas de crescimento ${ }^{a}$ dos tipos de famílias extensas pobres, segundo as Grandes Regiões redefinidas do Brasil (rural não-metropolitano), 1995-99.

\begin{tabular}{|l|l|l|l|l|l|}
\hline $\begin{array}{l}\text { TIPOS DE FAMÍLIAS } \\
\text { EXTENSAS POBRES }\end{array}$ & NE & SE - SP & SP & SU & CO \\
\hline Conta-Própria & 1,8 & $-8,8^{* * *}$ & $-11,8^{* * *}$ & $-4,2^{* * *}$ & $-2,3$ \\
\hline Agrícola & $-0,5$ & $-8,7^{* * *}$ & $-18,4^{* * *}$ & $-5,0^{* * *}$ & $-3,0^{*}$ \\
\hline Pluriativo & $5,3^{*}$ & $-11,2^{* *}$ & $-20,5$ & $-2,6$ & $-2,5$ \\
\hline não-agrícola & 2,8 & $-5,0$ & 6,8 & 11,0 & 3,1 \\
\hline & & & & & \\
\hline Assalariados & $2,6 * *$ & $-0,9$ & $-2,7^{*}$ & $1,8 *$ & $-1,3$ \\
\hline Agrícola & $-5,0$ & $-0,8$ & $-7,7^{* * *}$ & $-0,4$ & $-2,4$ \\
\hline Pluriativo & 14,7 & 1,3 & $-11,9^{*}$ & $-2,6$ & 0,4 \\
\hline não-agrícola & $13,7^{* * *}$ & $-2,9$ & $7,6 * *$ & $8,2 * * *$ & 1,5 \\
\hline
\end{tabular}

Nota: exclusive as famílias sem declaração de renda e tipos de família com menos de 5 observações

a) estimativa do coeficiente de uma regressão log-linear contra o tempo. Neste caso, o teste $t$ indica a existência ou não de uma tendência nos dados.

Tendência nos dados. $* * *, * *, *$ significam respectivamente $5 \%, 10 \%$ e $20 \%$ de significância.

Fonte: Tabulações Especiais do Projeto Rurbano, NEA-IE/Unicamp.

Verificamos que as explicações dadas acima são perfeitamente cabíveis para dar conta dos diferentes exemplos de redução e/ou estabilização da pobreza entre as famílias rurais abordadas acima. Entretanto, queremos chamar a atenção para alguns casos de redução da pobreza rural que não são elucidados suficientemente pelas explicações listadas anteriormente.

Se "cruzarmos" as Tabelas 1, 3 e 4 poderemos acrescentar mais duas explicações complementares possíveis para a redução e/ou estabilização da pobreza entre alguns tipos de famílias rurais em algumas regiões do país. A Tabela 3 apresenta as taxas de crescimento das famílias extensas pobres, segundo a nova tipologia de famílias extensas do Projeto Rurbano, ou seja, apresenta as famílias pluriativas e não-agrícolas em um nível de desagregação. A desagregação destas famílias em diferentes tipos nos permite perceber a importância da renda oriunda dos ser- 
viços domésticos remunerados para alguns contingentes de famílias rurais, em determinadas regiões do país.

Ao desagregarmos a pluriatividade e as famílias não agrícolas, podemos ver que a renda proveniente dos serviços domésticos remunerados tem forte peso explicativo para certas famílias. É o que tentaremos mostrar em seguida.

Desagregando as famílias pobres de conta-próprias pluriativas (Tabela 3), chama atenção que na região Sudeste a redução significativa das famílias pobres pluriativas deveu-se à redução também significativa das famílias pobres pluriativas com SDR (agrícola + SDR), da ordem de $12,0 \%$ a.a.

Em relação aos tipos de famílias pobres assalariadas, observa-se que apenas em São Paulo houve uma redução significativa das famílias pobres agrícolas $(7,7 \%$ a a) e pluriativas $(11,9 \%$ a a). Provavelmente a redução do contingente de famílias pobres pluriativas em São Paulo deveu-se à redução $(23,3 \%$ a a $)$ das famílias pobres pluriativas com SDR (agrícola + SDR), embora esta redução seja não significativa.

É interessante notar (ainda Tabela 3) que na região Nordeste foi a pluriatividade (agrícola + SDR) que atenuou a expansão (manteve a estabilidade) do quantitativo de famílias pobres pluriativas, seja de conta-própria, seja de assalariados, no período 1995-99, uma vez que os demais tipos de famílias pobres pluriativas presentes nessa região apresentaram fortes taxas de crescimento altamente significativas. Acreditamos que, neste caso, o peso das rendas decorrentes dos serviços domésticos remunerados tiveram mais expressividade do que as rendas governamentais (aposentadorias e pensões) para a referida observação - basta ver a composição das rendas média (e per capita) das famílias pluriativas com SDR, mostradas pelos gráficos 8 e 9 .

Nesse sentido, é importante observar também que enquanto os contingentes de famílias pluriativas (agrícola + SDR) nordestinas, de conta-próprias e de assalariados, aumentaram no período 1992-99 (Tabela 1) de forma significativa, a parcela desses contingentes que se encontravam abaixo da linha de pobreza referente à renda per capita de U\$ 1,08 por dia, reduziu-se no período 1995-99, indicando que o SDR, mesmo sendo considerado uma atividade típica de economias subdesenvolvidas e socialmente desiguais, contribuiu sensivelmente para al- 
çar uma parte das famílias pobres pluriativas nordestinas para a faixa das famílias não pobres, as quais percebem renda per capita acima de $\mathrm{U} \$ 1,08$ por dia.

O êxodo agrícola entre as famílias de assalariados (ver Tabela 1) nordestinas levou à redução da pobreza entre as famílias agrícolas, mas ao mesmo tempo levou ao aumento da pobreza entre as famílias de assalariados pluriativas e não agrícolas (Tabela 3), sem falar das famílias de não-ocupados. Conforme já dito, somente entre as famílias pobres de assalariados pluriativas nordestinas com SDR (agrícola + SDR) observou-se redução significativa.

É importante observar que também na região Sul o SDR pode ter contribuído para tornar não pobres uma parcela das famílias pobres de assalariados não-agrícolas que residem nas suas áreas rurais não metropolitanas. No Sudeste (sem São Paulo) e em São Paulo, a retração da pobreza (embora não significativa do ponto de vista estatístico) entre as famílias de assalariados não-agrícolas com SDR, em contraste com o crescimento significativo das famílias não-agrícolas sem trabalho doméstico, sugere que a renda do SDR contribuiu para conter a expansão das famílias não agrícolas em seu conjunto (somatório das famílias nãoagrícolas com e sem SDR). Foi o que não ocorreu entre as suas congêneres no Nordeste.

Queremos ainda acrescentar uma outra explicação no que diz respeito à redução das famílias pobres agrícolas no meio rural. Esta não somente decorre da substituição das atividades agrícolas pelas não agrícolas ou pelo êxodo rural-urbano (como sugerem Del Grossi et al,2002; e Graziano da Silva, 2000), mas também pelo crescimento das famílias rurais de não-ocupados (cujos membros todos encontram-se desocupados, porém, residentes no meio rural), como pode ser visto na Tabela 4. 
Tabela 3 - Taxas de crescimento ${ }^{a}$ dos tipos de famílias extensas pobres, segundo as Grandes Regiões (rural não-metropolitano), 1995-99.

\begin{tabular}{|c|l|l|l|l|l|}
\hline $\begin{array}{c}\text { TIPO DE FAMÍLIA } \\
\text { POBRE }\end{array}$ & \multicolumn{1}{|c|}{ NE } & SE - SP & SP & SU & CO \\
\hline Conta-Própria & 1,8 & $-8,8^{* * *}$ & $-11,8^{* * *}$ & $-4,2^{* * *}$ & $-2,3$ \\
\hline Agrícola & $-0,5$ & $-8,7^{* * *}$ & $-18,4^{* * *}$ & $-5,0^{* * *}$ & $-3,0$ \\
\hline Pluriativo & $5,3^{*}$ & $-11,2^{* *}$ & $-20,5$ & $-2,6$ & $-2,5$ \\
\hline Agrícola + Agricola & 1,0 & $-5,3$ & & $-25,3^{* * *}$ & 17,1 \\
\hline Agricola + Não Agricola & $8,5^{* *}$ & $-12,0$ & & 8,8 & $-11,4$ \\
\hline Agricola + SDR & $-5,1^{*}$ & $-12,0^{*}$ & & 22,1 & 19,4 \\
\hline Agric + Não Agric + SDR & $15,7^{*}$ & $* * *$ & & & \\
\hline Não Agrícola & $2,8^{*}$ & $-5,0$ & 6,8 & 11,0 & 3,1 \\
\hline Não Agrícola sem SDR & 2,5 & $-4,9$ & 6,8 & 13,0 & 3,3 \\
\hline Não Agrícola com SDR & 13,4 & $-1,0$ & & & $-1,2$ \\
\hline & & & & & \\
\hline Assalariados & $2,6 * *$ & $-0,9$ & $-2,7$ & $1,8 *$ & $-1,3$ \\
\hline Agrícola & $-5,0$ & $-0,8$ & $-7,7 * * *$ & $-0,4$ & $-2,4$ \\
\hline Pluriativo & $14,7^{*}$ & 1,3 & $-11,9 *$ & $-2,6$ & 0,4 \\
\hline Agricola + Não Agricola & $20,8^{*}$ & 1,5 & & $-2,9$ & $-5,4$ \\
\hline Agricola + SDR & $-4,9^{* * *}$ & $-0,2$ & $-23,3$ & 0,8 & 4,9 \\
\hline Agric + Não Agric + SDR & $23,5^{* *}$ & 12,1 & & & \\
\hline Não Agrícola & $13,7^{* * *}$ & $-2,9$ & $7,6 * *$ & $8,2 * * *$ & 1,5 \\
\hline Não Agrícola sem SDR & $13,7^{* * *}$ & $-1,9$ & $15,2 * * *$ & $15,2 * * *$ & 1,0 \\
\hline Não Agrícola com SDR & $13,4^{* * *}$ & $-4,5$ & $-1,0$ & $-11,4 *$ & 3,1 \\
\hline
\end{tabular}

Nota: exclusive as famílias sem declaração de renda e tipos de família com menos de 5 observações

a) estimativa do coeficiente de uma regressão log-linear contra o tempo. Neste caso, o teste $t$ indica a existência ou não de uma tendência nos dados.

nos dados. $\quad * * *, * *, *$ significam respectivamente $5 \%, 10 \%$ e $20 \%$ de significância. Fonte: Tabulações Especiais do Projeto Rurbano, NEA-IE/Unicamp.

Não obstante o fato de termos sugerido que em algumas regiões certas famílias deixaram de ser agrícolas e passaram diretamente a ser não-agrícolas (Tabela 1), não significa que desconsideramos a possibilidade concreta de substanciais parcelas daquelas famílias estarem engrossando as fileiras do crescente contingente de famílias de não-ocu- 
pados, uma vez que este tipo familiar apresentou elevadas taxas de crescimento altamente significativas no período analisado, nas áreas rurais de todas as Grandes Regiões do país - exceto no Nordeste, indicando que apenas nesta região as áreas rurais agropecuárias ainda não representam um espaço de busca por novos "usos”, quais sejam: moradia para não-ocupados, especialmente aposentados e pensionistas, etc. (Tabela $4^{20}$ ). Esta realidade revela a importância de se considerar esta questão nas formulações de políticas de desenvolvimento rural no Brasil, principalmente para as regiões mais pobres como é o caso da região Nordeste.

Tabela 4 - Evolução do total das famílias extensas e das famílias de não-ocupados, segundo as Grandes Regiões (rurais nãometropolitanos), 1992-1999. (1.000 famílias)

\begin{tabular}{|c|c|c|c|c|}
\hline $\begin{array}{c}\text { GRANDES } \\
\text { REGIÕES }\end{array}$ & $\begin{array}{c}\text { Não-Ocup } \\
1992\end{array}$ & $\begin{array}{c}\text { Não-Ocup } \\
1999\end{array}$ & $\begin{array}{c}\text { tx cresc fam } \\
\text { Não-Ocup } \\
1992 / 1999^{a}\end{array}$ & $\begin{array}{c}\text { tx cresc do } \\
\text { tot fam } \\
1992 / 1999^{a}\end{array}$ \\
\hline NE & 290 & 292 & $1,77^{* * *}$ & $1,0^{* * *}$ \\
\hline SE - SP & 73 & 122 & $9,0^{* * *}$ \\
\hline SP & 21 & 53 & $12,4^{* * *}$ & $2,2^{* * *}$ \\
\hline SU & 73 & 110 & $6,44^{* * *}$ & $0,2^{* *}$ \\
\hline CO & 17 & 29 & $12,3^{* * *}$ & $2,0^{* * *}$ \\
\hline
\end{tabular}

a) Estimativa do coeficiente de uma regressão log-linear contra o tempo. Neste caso, o teste $\mathrm{t}$

Indica a existência ou não de uma tendência nos dados.

$* * *, * *, *$ significam respectivamente $5 \%, 10 \%$ e $20 \%$ de significância.

Fonte: Nascimento, 2002.

\section{6 - Considerações finais}

Como se pôde ver, em praticamente todas as Grandes Regiões redefinidas do país existem casos específicos de famílias rurais pobres (pluriativas ou não-agrícolas) entre as quais a renda oriunda de servi-

\footnotetext{
${ }^{20}$ É importante perceber também que as famílias de não ocupados cresceram bem mais rapidamente do que os totais de famílias residentes nos rurais agropecuários das respectivas regiões - exceto Nordeste -, no período 1992-1999.
} 
ços domésticos remunerados certamente teve uma decisiva participação para a redução e/ou estabilização da pobreza rural entre aqueles diferentes contingentes familiares. Um fator que ajuda a sustentar estas considerações é o fato de que na grande maioria dos casos observados de composição da renda média familiar (igual à composição da renda média per capita familiar), a participação da renda dos serviços domésticos evidenciou-se com maior peso do que as rendas governamentais (aposentadorias e pensões) - gráficos 7 e 8.

Os resultados apontados neste estudo sobre o importante papel das rendas dos serviços domésticos remunerados para determinados tipos de famílias extensas rurais - seja para mantê-las vinculadas à terra com uma atividade agrícola (Nascimento, 2002), seja para alçá-las para cima da linha de pobreza adotada (U\$1,08), em todas as Grandes Regiões redefinidas - podem servir de subsídio para a difícil luta das organizações sindicais das domésticas por um tratamento indiferenciado, do ponto de vista jurídico-trabalhista, em relação a todas as outras categorias de trabalhadores. Segundo Gorz (1989), o SDR deveria ser feito por todos e todos deveriam ter acesso às atividades produtivas. Entretanto, enquanto esta "utopia" não se realiza as trabalhadoras domésticas precisam conquistar o reconhecimento, perante a Lei, de que são uma categoria de trabalhadores como qualquer outra e adquirir todos os direitos já concedidos às demais categorias.

Não obstante o SDR não ser considerado uma atividade produtiva do ponto de vista social (Gorz, 1989), tem se constituído numa forma de transferência de renda e representa hoje a única fonte de emprego para milhares de mulheres que não têm outra oportunidade de inserção no mercado de trabalho (Pereira de Melo, 1998). No contexto de crise social pela qual passa o Brasil, o emprego doméstico deve ser visto como uma das formas alternativas de emprego capaz de absorver parte da mão-de-obra excedente gerada pelo desenvolvimento capitalista no campo. Urge, portanto, estender aos empregados domésticos os mesmos direitos já conquistados pelas demais categorias de trabalhadores assalariados, especialmente o amparo do FGTS e a obrigatoriedade da sindicalização. (Graziano da Silva, 2002: 13).

Em acréscimo a esta evidência do destaque dos serviços domésticos remunerados entre muitas famílias rurais, vimos também o rápido cres- 
cimento das famílias rurais de não-ocupados nos anos 90, enfatizando o grau de estagnação da economia brasileira que não tem sido capaz de absorver os excedentes de mão-de-obra agrícola, seja no meio urbano, seja no meio rural. Enfim, o crescimento de serviços domésticos remunerados e de famílias de não-ocupados no meio rural, em contraste com a continuada retração da ocupação agrícola, reforçam as evidências do aumento da pobreza e da desigualdade social (pessoal e regional) em nosso país.

\section{7 - Referências Bibliográficas}

DEL GROSSI, M. E., GRAZIANO DA SILVA, J., TAKAGI, M. (2002). Evolução da pobreza rural, 1995-1999. IE/Unicamp. Projeto Rurbano (mimeo).

DEL GROSSI, M. E. \& GRACIANO DA SILVA, J. (1998). A pluriatividade na agropecuária brasileira em 1995. Estudos Sociedade e Agricultura, n.11, out. 1998. p. 26-52.

DELGADO, G., CARDOZO JR, R. C. (2000). A universalização dos direitos sociais no Brasil: a previdência rural nos anos 90 . Brasília, IPEA, p. 417-440.

FERNANDES FILHO, J. F. (2001). Indústria rural no Nordeste e no Brasil e o desenvolvimento do espaço rural. Revista Econômica do Nordeste. Fortaleza-CE, v.32, p. 1-26.

GORZ, A. (1989). Critique of economic reason. Great Britain. Bookcraft (Bath) Ltd.

GORZ, A. (2003). Metamorfoses do trabalho: crítica da razão econômica (tradução de Ana Montoia). São Paulo: Annablume. 248p.

GRAZIANO DA SILVA, J. (2002). Prefácio, in: BALSADI, O. V. (2002). Mudanças rurais e o emprego no estado de São Paulo nos anos 90. São Paulo: Annablume, 156p. 
GRAZIANO DA SILVA, J., DEL GROSSI, M. E. (2001). Rural nonfarm employment and incomes in Brazil: Patterns and evolution. World Development, Great Britain. 29 (3): 443-454 (march).

GRAZIANO DA SILVA, J., DEL GROSSI, M. E., CAMPANHOLA, C. (2000). O Fim do Êxodo Rural?. Versão preliminar, para discussão - Projeto Rurbano - Fase III, IE/UNICAMP, Campinas, dezembro de 2000.

KAGEYAMA, A. A. (2001). Determinantes das condições socioeconômicas dos domicílios agrícolas no Brasil. (Relatório parcial de pesquisa). Campinas, SP. IE-UNICAMP. (mimeo)

LIMA, A. A. (2001). A agroindústria canavieira alagoana: da criação do IAA à desregulamentação na década de 1990. Campinas, SP. IE-UNICAMP. (dissertação de mestrado)

MARTINS, S. P. (2000). Manual do Trabalho Doméstico. 5a ed. São Paulo. Atlas. (Coleção temas jurídicos), 162p.

MENDRAS, H (1984). “O Fim dos Camponeses" - "Passados vinte anos”. (prefácio traduzido pela professora Marisa Rossetto, em julho, 2000).

NASCIMENTO, C. A. (2002). Evolução das famílias extensas no Brasil e Grandes Regiões: pluriatividade e trabalho doméstico, 19921999. Campinas, SP: IE/Unicamp. (dissertação de mestrado)

NASCIMENTO, C. A., PEREIRA, C. F., GRAZIANO DA SILVA, J., DEL GROSSI, M. E. (2001). Pluriatividade e emprego doméstico no meio rural do Brasil, 1992-1999. ANAIS do XXXIX Congresso Brasileiro de Economia e Sociologia Rural - SOBER. Recife, PE. p. 139.

PEREIRA DE MELO, H. (1998). O Serviço Doméstico Remunerado no Brasil: de criados a trabalhadores. in: Cinco Estudos de Casos sobre Serviços no Brasil. Rio, MICT. pp. 120-143. 
POCHMANN, M (2001). A década dos mitos. São Paulo: Contexto. $182 p$.

TAKAGI, M., GRAZIANO DA SILVA, J., DEL GROSSI, M. E. (2001). Pobreza e Fome: em busca de uma metodologia para quantificação no Brasil. Campinas, SP: IE/UNICAMP, jul 2001. (Texto para Discussão nr 101)

Recebido em agosto de 2003 e revisto em fevereiro de 2004. 